\title{
Pneumatic ABS Modeling and Failure Mode Analysis of Electromagnetic and Control Valves for Commercial Vehicles
}

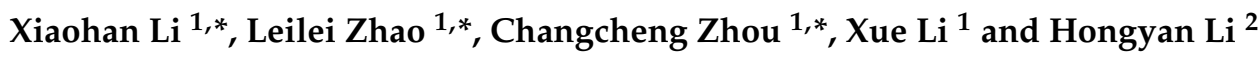 \\ 1 School of Transportation and Vehicle Engineering, Shandong University of Technology, 12 Zhangzhou Road, \\ Zibo 255049, China; 15552671715@163.com \\ 2 State Key Laboratory of Automotive Simulation and Control, Jilin University, Changchun 130022, China; \\ shanligongdaxue@126.com \\ * Correspondence: xhan_lee@163.com (X.L.); zhaoleilei611571@163.com (L.Z.); greatwall@sdut.edu.cn (C.Z.); \\ Tel.: +86-1358-958-9324 (X.L.)
}

Received: 30 December 2019; Accepted: 6 February 2020; Published: 12 February 2020

\begin{abstract}
A failure of the pneumatic ABS (anti-lock braking system) weakens the braking performance of commercial vehicles. It affects the driving safety of vehicles. There are four typical failure modes that include: the failure of the pilot inlet solenoid valve and pilot exhaust solenoid valve of the pressure regulator, the failure of the series dual-chamber brake valve, and the failure of the relay valve. In order to study the braking performance and the rule of vehicles under the failure modes of the pneumatic ABS, the co-simulation model of the pneumatic ABS of the commercial vehicle was established based on AMESim and Simulink softwares. The gas path subsystem of the pneumatic ABS and the vehicle model were built based on AMESim. The controller was established based on Simulink/Stateflow. The data were transmitted between the AMESim and Simulink software by using the data interface block. The co-simulation model was validated by tests. The results showed that the maximum error of the braking deceleration is $13.51 \%$. The model can simulate the braking process of the vehicle well. Based on this, the four typical failure modes of the pneumatic ABS were simulated, and the influences of different failure modes on the braking ability were analyzed. The influence of failure ratio on braking distance in four modes was obtained. It can be seen from the simulation results that the failure of the pilot inlet solenoid valve and the pilot exhaust solenoid valve of the pressure regulator cause the wheel lock. The failure of the lower chamber of the brake valve and the failure of the relay valve have a great influence on the braking distance.
\end{abstract}

Keywords: commercial vehicles; pneumatic ABS; solenoid valve; co-simulation; test; failure mode; braking process

\section{Introduction}

The pneumatic ABS (anti-lock braking system) is widely used in trucks, buses, and other commercial vehicles. It can prevent wheels from locking, make full use of the ground adhesion, and maintain steering ability in emergency braking to avoid danger. ABS have become a standard on commercial vehicles. The power transmission medium of the pneumatic ABS is air. Air has a strong compressibility. The pressure response of the brake chamber has a strong hysteresis. The failure of the pneumatic ABS parts weakens the braking performance of vehicles.

In references [1,2], the modeling and the simulation of the ABS were carried out based on MATLAB/Simulink. Ma et al. established the model of the pressure regulator of the pneumatic ABS [3]. Qingnian Wang et al. established the simulation model of ABS of an electric vehicle driven by the hub motor, and designed the control strategy [4]. Zhao et al. analyzed the response characteristics 
of the braking pressure of the ABS hydraulic subsystem based on AMESim [5]. Wang established a co-simulation model of the four-channel hydraulic ABS based on AMESim and Simulink softwares. The simulation was carried out on a low-adhesion road [6,7]. Lu et al. studied the pressure characteristics of the proportional relay valve of the EBS (Electronically Controlled Brake System) [8]. Kong built a pneumatic ABS model in Simulink, designed the controller with finite state machine, built a test bed, verified the model [9]. Lin et al. designed a fuzzy controller of the electric vehicle ABS. The co-simulation model was established in Simulink and AMESim [10].

Liu et al. established an ABS simulation model by using MATLAB/Simulink, including the tire model, the brake model. The PID (Proportional-Integral-Derivative) control strategy was designed [11]. Chen established a co-simulation model of pneumatic ABS based on TruckSim, Simulink, and AMESim. The control input variable was the air pressure of the brake chamber, and the output was the displacement of the brake pedal. The control strategy does not conform to the reality. No research on the ABS braking effect was performed [12]. Zheng established the CARIMA (Controlled Autoregressive Integrated Moving Average) model of the pneumatic ABS. The reference trajectory equation and the objective function equation were established with the wheel slip ratio as the control objective [13].

Zhao et al. established a sliding mode control model of the regenerative braking system equipped with the pneumatic ABS for buses [14]. Minh built the ABS test-bed, designed a fuzzy controller and a PID controller, and compared the two control strategies through experiments [15]. Naderi et al. designed ASR and ABS controllers based on fuzzy control strategy and sliding mode control strategy in MATLAB, and verified their effectiveness [16]. Majid Mokarram et al. used the CMOS circuit and the adaptive neuro-fuzzy inference system to optimize the ABS fuzzy controller [17]. Dang built a fuzzy control model and a PID control model of single-wheel ABS based on Simulink, and compared the two strategies [18].

Gu et al. studied the air pressure response characteristics of the brake pipe through experiments [19]. $\mathrm{Chu}$ et al. simulated the dynamic characteristics of the pneumatic ABS pressure regulator using Matlab/Simulink, and carried out a hardware-in-the-loop experiment [20]. Tao proposed a dynamic logic threshold control strategy with good performance [21]. Natarajan et al. established a mathematical model of the relay valve of the pneumatic brake system and conducted experimental verification [22]. Zhang built a total model including air tanks, brake valves, relay valve, ABS pressure regulators, and brake chambers in simulation software MWworks based on Modelica programming language [23]. Meng et al. built a pneumatic ABS pressure regulator model in AMESim, and carried out static dynamic analysis. The model has been tested and verified to have high reliability [24,25].

Hu improved the traditional threshold logic control algorithm, and designed a pneumatic ABS controller based on Stateflow. The correctness of the control algorithm was verified by the XPC Target platform that was built based on Matlab/Simulink [26]. Jung et al. established a prediction model of the braking system by using the programming and the database. The parameters of the load-sensing valve were able to be changed. The design efficiency of the braking system was improved [27]. Tao et al. established a model of the metro relay valve in AMESim and simulated the failure conditions [28]. Ji et al. studied basic principles and methods of automobile ABS fault analysis based on fuzzy diagnosis technology [29]. Yang et al. studied the failure causes of the pneumatic ABS pressure regulator of electric buses, and extended its service life by optimizing the structural design of the solenoid valve [30]. At present, there is no research by scholars and researchers on the braking performance of commercial vehicles under the failure conditions such as failure of pilot solenoid valves of ABS pressure regulators, the brake valve, and the relay valve. Therefore, further research on the above failure modes has engineering significance.

The first part of this paper introduces the structure and working principle of the pneumatic ABS. In the second part, the submodels and the total model are built based on AMESim and Simulink. The third part carries out the simulation verification of submodels and the total model. In the fourth part, four failure modes including the failure of the pilot inlet solenoid valve and pilot exhaust solenoid 
valve of the ABS pressure regulator, the failure of the series dual-chamber brake valve, and the failure of the relay valve, are analyzed.

\section{Working Principle of the Pneumatic Anti-Lock Braking System (ABS)}

A pneumatic ABS of commercial vehicles usually includes pneumatic parts, electronic parts and mechanical parts, etc. The basic structure of the pneumatic ABS is shown in Figure 1. The air compressor, 1 , is powered by the engine. The high-pressure air is fed into the primary air reservoir from the compressor. The front and rear brake devices are supplied with high-pressure air respectively by the series dual-chamber air brake valve, 10, from two independent air reservoirs, 8 and 9 [31].

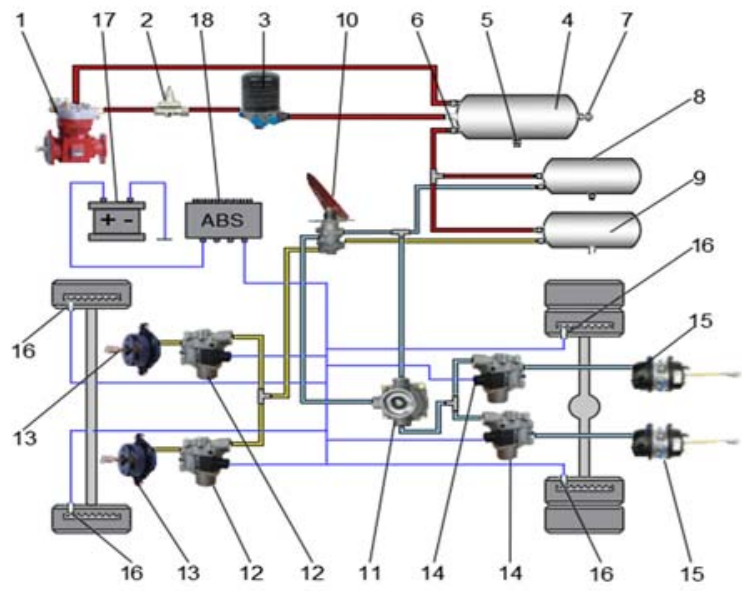

Figure 1. Schematic diagram of the pneumatic anti-lock braking system (ABS). 1-air compressor; 2-pressure limiting valve; 3-air dryer; 4-primary air reservoir; 5 -drainage valve; 6-one-way valve; 7-relief valve; 8-air reservoir for rear brake; 9-air reservoir for front brake; 10-series dual-chamber brake valve; 11-relay valve; 12 -front pressure regulator; 13 -front brake; 14 -rear pressure regulator; 15 -rear brake; 16-wheel rotary speed sensor; 17-power supply; 18-ECU (Electronic Control Unit).

When the brake pedal is depressed, the high-pressure air in the front brake air reservoir 9 enters the front $\mathrm{ABS}$ pressure regulator 12 through the lower chamber of the brake valve 10 , and then enters the front brake chamber 13. The high-pressure air in the air reservoir 8 is divided into two parts, one enters the inlet port of the relay valve 11 directly, and the other passes through the upper chamber of the brake valve 10 to enter the control port of the relay valve 11, so that the relay valve is turned on. Then the high-pressure air enters the rear brake chamber 15 through the rear ABS regulator 14 from the relay valve. The ECU calculates the wheel angular speed, the wheel angular acceleration, the slip ratio, and the velocity of vehicle according to the signal of wheel speed sensor. Then, it outputs the control signals of ABS pressure regulator of the corresponding wheel. By the control of the ECU, the pressures of brake chambers can be adjusted to prevent wheels from locking [23].

\section{Model Establishment}

The submodels of a pneumatic system and the vehicle were built in AMESim software. The controller submodel was established in Simulink. The control strategy was designed based on Stateflow. The data interaction was realized by simulation interface modules in AMESim and Simulink. The total model was established by connecting the submodels.

\subsection{Modeling of Submodels}

Components of the pneumatic ABS are from different physical fields [23]. AMESim is a multidisciplinary and complex field simulation platform that is widely used in modeling and simulation of complex systems [32,33]. The pneumatic submodels were built using components of the 
mechanical library, the pneumatic library, and the signal control library of AMESim. The system is a composition of several basic typical components, and each component has relatively independent dynamic characteristics [23]. Next, the modeling of three valves that will be studied are introduced.

\subsubsection{Modeling of the Series Dual-Chamber Air Brake Valve}

The series dual-chamber air brake valve makes the front and rear brake lines independent of each other to ensure braking safety [12]. The piston motion clearance is simulated by the component LSTP00A. The piston mass and the limit stroke are simulated by the component MAS005RT. The upper chamber, the lower chamber, and the return spring are simulated by the component PNPA003. The inlet and outlet are simulated by the component PNAO001. The appearance, structure, and submodel of the series dual-chamber air brake valve are shown in Figure 2.

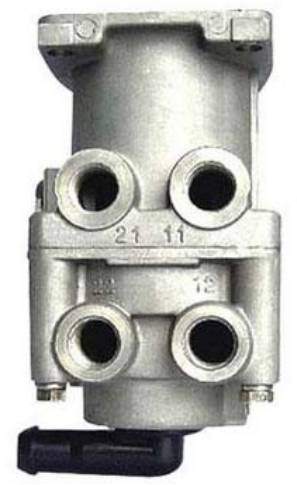

(a)

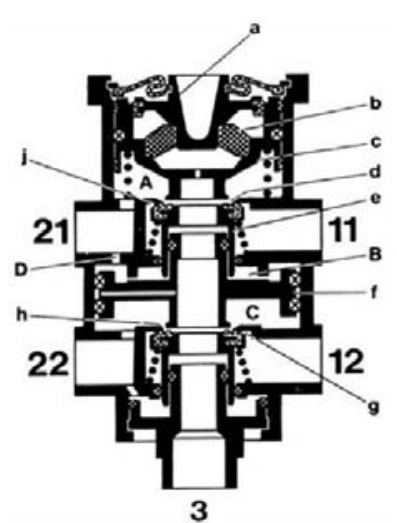

(b)

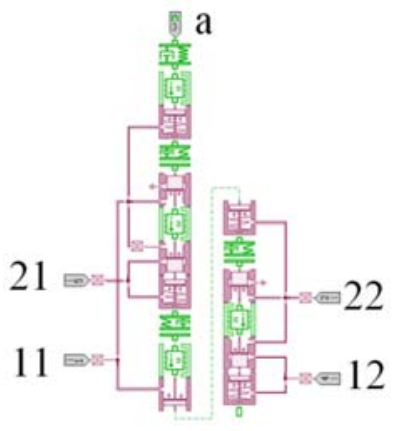

(c)

Figure 2. Series dual-chamber air brake valve. (a) Appearance. (b) Schematic diagram. (c) Submodel in AMESim. In the schematic diagram: a-tappet seat; b-rubber spring; c-upper chamber piston; d-upper chamber exhaust port; e-valve stem; f-lower chamber piston; g-lower chamber inlet; h-lower chamber exhaust port; i-upper chamber inlet; A,B,C-chamber; D-flow hole; 11-upper chamber inlet port; 21-upper chamber outlet port; 12-lower chamber inlet port; 22-lower chamber outlet port; 3-exhaust port.

\subsubsection{Modeling of the Relay Valve}

The relay valve can make air enter the rear brake chamber from the rear brake air reservoir through the relay valve and the ABS pressure regulator without passing through the series dual-chamber air brake valve, thereby reducing rear brake response time. The appearance, structure, and submodel of the relay valve are shown in Figure 3 [22].

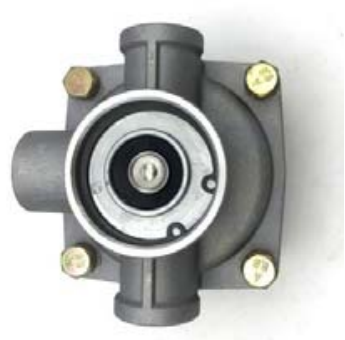

(a)

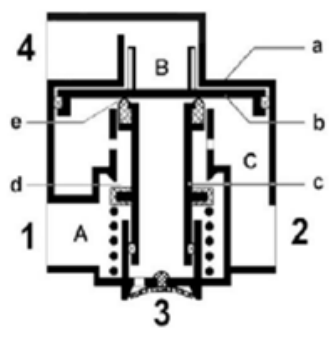

(b)

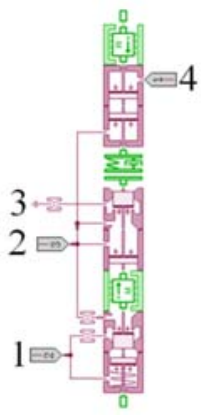

(c)

Figure 3. Relay valve. (a) Appearance. (b) Schematic diagram. (c) Submodel in AMESim. In the Schematic diagram: 1-air inlet port; 2-air outlet port; 3-air exhaust port; 4-control port; a-valve body; b-piston; c-valve stem; d-inlet; e-exhaust valve; A-inlet chamber; B-control chamber; C-outlet chamber. 
The port 4 connects to the air outlet port 21 of the upper chamber of the brake valve. The port 1 connects to the air reservoir 8 . The port 2 connects to the rear pressure regulators. The chamber $\mathrm{B}$ and $\mathrm{C}$ are simulated by the component PNPA002. The inlet and outlet are simulated by the component PNAP031. The piston mass and the limit stroke are simulated by the component MAS005RT. The piston motion clearance is simulated by the component LSTP00A. When the air enters the chamber B, the piston $b$ moves downward, and the inlet $d$ is opened. Then the air enters the rear pressure regulators through the chamber $\mathrm{A}$, inlet $\mathrm{d}$, chamber $\mathrm{C}$, and port 2 .

\subsubsection{Modeling of the Pneumatic ABS Pressure Regulator}

The pneumatic ABS pressure regulator uses solenoid valves as pilot valves and is a kind of direct-controlled gas pressure regulator. There are two solenoid valves inside the ABS pressure regulator. By controlling the on-off combination of the two pilot solenoid valves, the working states of ABS pressure regulator can be in rapid charging, rapid releasing, step charging, step releasing and pressure holding. The appearance, structure, and submodel of the ABS pressure regulator are shown in Figure 4. [25]. The working principle of ABS pressure regulator is shown in Table 1.

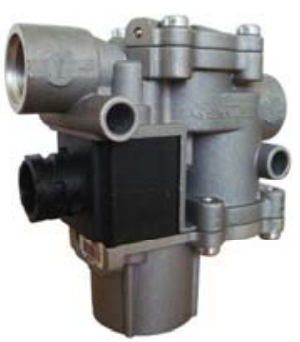

(a)

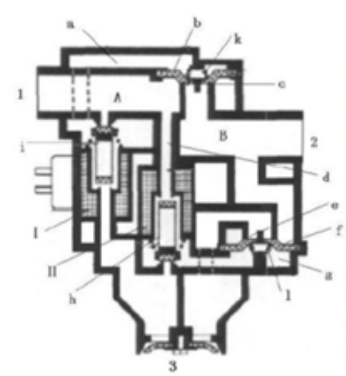

(b)

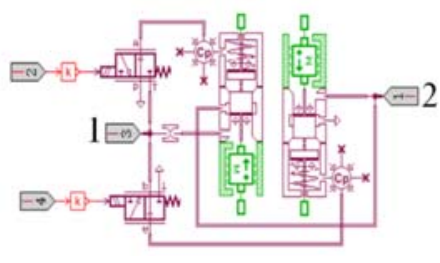

(c)

Figure 4. Pneumatic ABS solenoid valve. (a) Appearance. (b) Schematic diagram. (c) AMESim submodel. In the schematic diagram: 1-from braking valve; 2-to braking chamber; 3-to atmosphere; a-pilot chamber(inlet valve); $b$-inlet valve diaphragm; c-inlet valve seat; $d$-air pilot passage; e-exhaust valve seat; f-exhaust valve diaphragm; g-pilot chamber(exhausted valve); h-pilot exhaust solenoid valve spool; i-pilot inlet solenoid valve spool; k-inlet valve spring; l-exhaust valve spring; I,II-solenoid; A-inlet chamber; B-outlet chamber.

Table 1. Working states of the pneumatic ABS pressure regulator.

\begin{tabular}{ccc}
\hline $\begin{array}{c}\text { Coil of Inlet Solenoid Valve/ } \\
\text { State of Inlet Valve }\end{array}$ & $\begin{array}{c}\text { Coil of Exhaust Solenoid } \\
\text { Valve/State of Exhaust Valve }\end{array}$ & Brake Chamber Pressure \\
\hline power off/open & power off/close & rapid charging \\
power on/close & power on/open & rapid releasing \\
power on/close & power off/close & pressure holding \\
pause power on/cycle open and & power off/close & step charging \\
power on/close & pause power on/cycle open and \\
close & step releasing \\
\hline
\end{tabular}

The chamber a is simulated by the component $\mathrm{PNCH} 012$. The pilot solenoid valve is simulated by the component PNSV231_05. The inlet valve and the exhaust valve are simulated by the component PNAO011. In the submodel, gain modules are input control signals of pilot solenoid valves.

\subsubsection{Modeling of the Controller}

The Stateflow product is an interactive graphical design tool that works with Simulink software to model and simulate event-driven systems, also called reactive systems. Event-driven systems transition from one operating mode to another in response to events and conditions [34]. The controller 
submodel includes a slip ratio calculation module and a control signal calculation module, as shown in Figure 5. The slip ratio, angular velocity, and angular acceleration are input to the Stateflow. Stateflow outputs control signals of the pilot inlet solenoid valves and the pilot exhaust solenoid valves. Stateflow is triggered by a pulse signal.

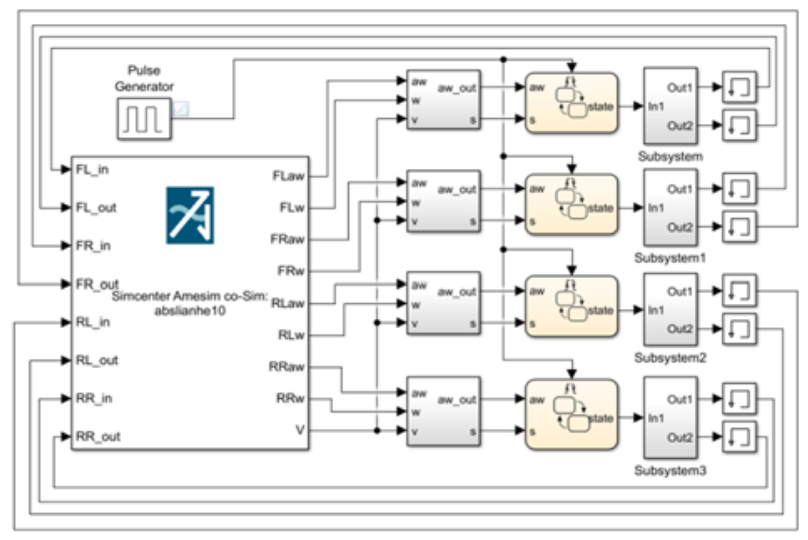

Figure 5. Controller submodel of the pneumatic ABS in Simulink.

The controller adopts a logic threshold control strategy. In this strategy, the threshold is set by two factors: slip ratio and wheel angular acceleration. The control logic is shown in Figure $6[35,36]$.

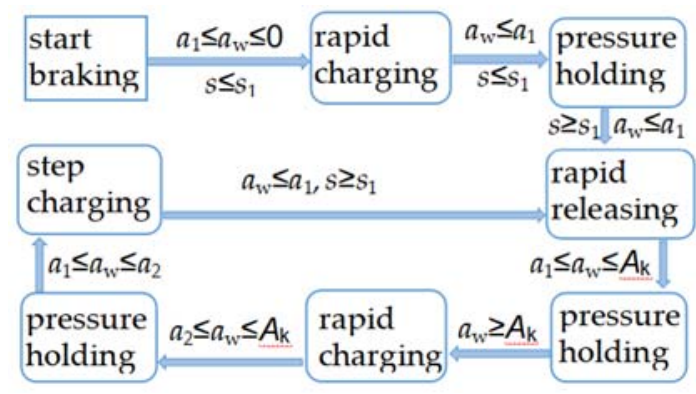

Figure 6. ABS logic threshold method control logic. $s_{1}$-slip ratio threshold, $a_{\mathrm{w}}$-angular acceleration, $a_{1}$-first threshold of angular acceleration, $a_{2}$-second threshold of angular acceleration, $A_{\mathrm{k}}$-third threshold of angular acceleration.

\subsection{Establishment of the Total Model}

The submodels in AMESim and Simulink are connected according to the topology as shown in Figure 7. [6]. The total model is shown in Figure 8. For the convenience of modeling, super components or subsystems are created for some complex submodels. The vehicle model uses the component TR3DCARB01. The wheel model uses the component TR3DTIRE01. The tire pavement model uses the component VDROAD00. And the tire pavement contact model uses the component VDADHER00. The properties of the air is defined by the component PNGD_AIR. 


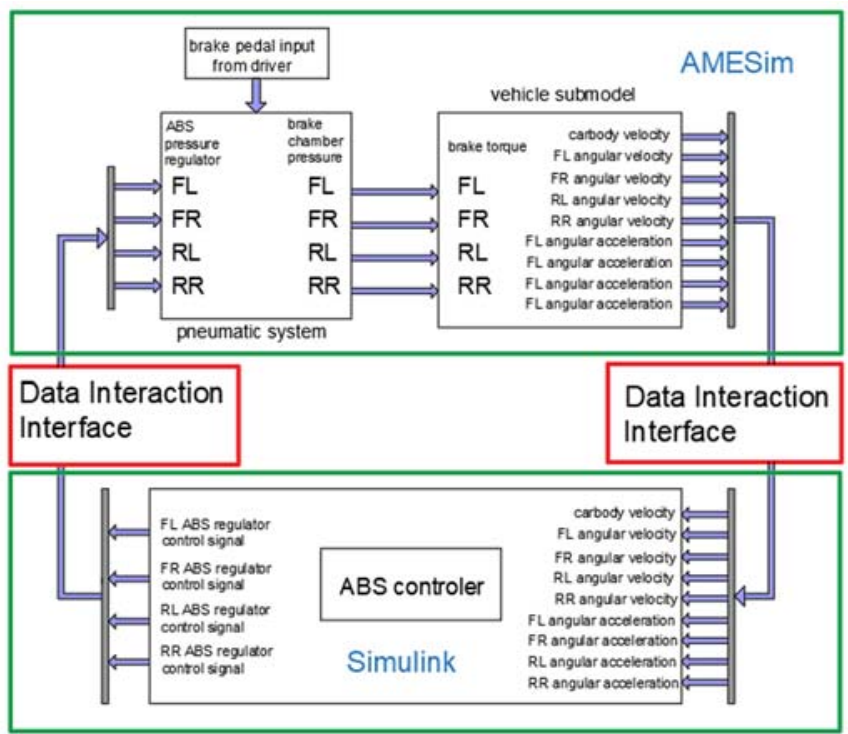

Figure 7. Simulation model topology.

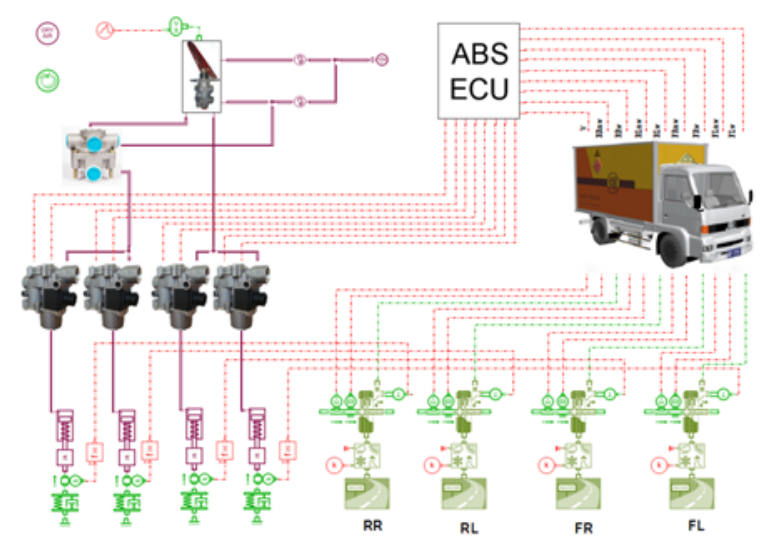

Figure 8. Total model of simulation.

In the co-simulation, there are many data exchanges and transmission among different softwares [27]. The data transfer module in Simulink is the Simcenter AMESim co-Sim module. In AMESim, is the interface block of SimuCosim module. The data are the vehicle speed, wheel angular velocity, wheel angular acceleration, and control signals of the inlet and outlet solenoid valves of each ABS pressure regulator. The co-simulation data interfaces are shown in Figure 9.

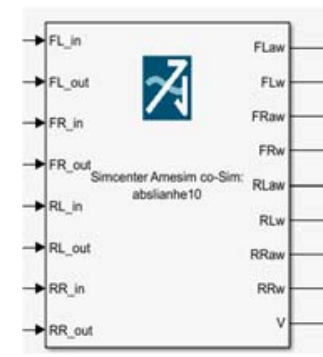

(a)

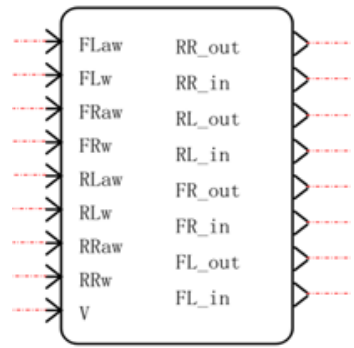

(b)

Figure 9. Interface block of co-simulation. (a) Simcenter Amesim co-Sim Module in Simulink; (b) Interface block of SimuCosim in AMESim. 


\section{Model Verification}

In this section, submodels are simulated and verified by comparing the simulation and experimental results. Then the total model is simulated and verified by comparing the simulation and the hardware-in-the-loop test data.

\subsection{Verification of the Pneumatic ABS Pressure Regulator Model}

The pressure of the air source was set to $0.64 \mathrm{MPa}$, the brake chamber volume to $2 \mathrm{~L}$, the temperature to $293.15 \mathrm{~K}$. The simulation step was set to $0.01 \mathrm{~s}$, simulation time to $5 \mathrm{~s}$. Firstly, kept the process of rapid charging going for $2 \mathrm{~s}$. Then, held the pressure for 1s. Finally, the process of rapid releasing was kept going for $2 \mathrm{~s}$. The curves of electrical control signals of pilot solenoid valves and the pressure response of brake chamber are shown in Figure 10.

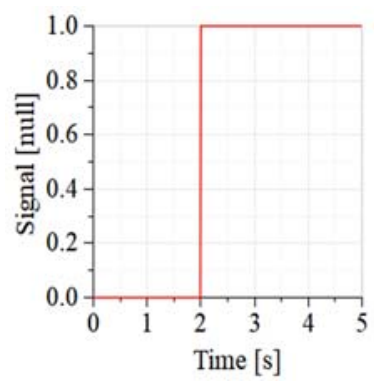

(a)

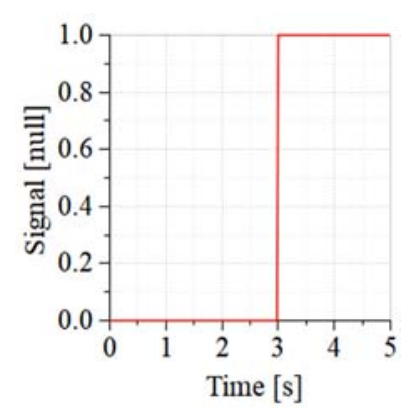

(b)

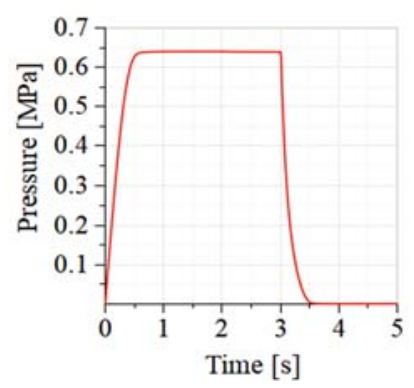

(c)

Figure 10. Curves of ABS pressure regulator control signal and pressure response of brake chamber. (a) Control signal of the pilot inlet solenoid valve; (b) control signal of the pilot exhaust solenoid valve;

(c) pressure of the brake chamber under control signals of $(\mathbf{a}, \mathbf{b})$.

The pressure of air source of the test bench was set to $0.64 \mathrm{MPa}$. When the brake chamber reached a steady state value of $0.64 \mathrm{MPa}$, a venting test was performed. Then the data of brake chamber pressure were obtained [12]. The results of the simulation and the test are shown in Tables 2 and 3 . The test data was extracted from curves in reference [12]. In order to facilitate the comparison of the test data, the third second in the simulation was marked as the start time as the releasing process. According to the comparison results, the simulation data are basically consistent with the trend of the test data. The maximum relative error was $16.0 \%$. The steady values of pressure were almost equal. Therefore, the model is considered to be reliable.

Table 2. Comparison of the simulation and test of rapid charging process.

\begin{tabular}{ccccccccccccc}
\hline Time(s) & $\mathbf{0 . 0 5}$ & $\mathbf{0 . 1}$ & $\mathbf{0 . 1 5}$ & $\mathbf{0 . 2}$ & $\mathbf{0 . 2 5}$ & $\mathbf{0 . 3}$ & $\mathbf{0 . 3 5}$ & $\mathbf{0 . 4}$ & $\mathbf{0 . 4 5}$ & $\mathbf{0 . 5}$ & $\mathbf{0 . 5 5}$ & $\mathbf{0 . 6}$ \\
\hline Simulation (MPa) & 0.087 & 0.169 & 0.249 & 0.328 & 0.403 & 0.470 & 0.527 & 0.571 & 0.604 & 0.623 & 0.633 & 0.639 \\
Test (MPa) & 0.090 & 0.180 & 0.270 & 0.340 & 0.420 & 0.480 & 0.540 & 0.580 & 0.610 & 0.630 & 0.640 & 0.640 \\
Relative error(\%) & 3.3 & 6.1 & 7.8 & 3.5 & 4.0 & 2.1 & 2.4 & 1.5 & 1.0 & 1.1 & 1.1 & 0.2 \\
\hline
\end{tabular}

Table 3. Comparison of the simulation and test of rapid releasing process.

\begin{tabular}{ccccccccc}
\hline Time(s) & $\mathbf{0}$ & $\mathbf{0 . 0 5}$ & $\mathbf{0 . 1}$ & $\mathbf{0 . 1 5}$ & $\mathbf{0 . 2}$ & $\mathbf{0 . 2 5}$ & $\mathbf{0 . 3}$ & $\mathbf{0 . 3 5}$ \\
\hline Simulation (MPa) & 0.639 & 0.472 & 0.295 & 0.187 & 0.116 & 0.068 & 0.035 & 0.011 \\
Test (MPa) & 0.640 & 0.460 & 0.270 & 0.170 & 0.100 & 0.060 & 0.030 & 0.010 \\
Relative error(\%) & 0.2 & 2.6 & 9.3 & 10.0 & 16.0 & 13.0 & 16.7 & 10.0 \\
\hline
\end{tabular}

The duty cycle of the signal was set from 0 to $100 \%$ with the interval $10 \%$. Then the dynamic curves of pressure at different duty cycles was obtained, as shown in Figure 11. It can be seen from the 
simulation results, pressure charging and releasing rates can be obtained by changing the PWM (Pulse Width Modulation) duty cycle of pulse energization [25]. The model can simulate the process of rapid charging, rapid releasing, pressure holding, step charging, and step releasing.

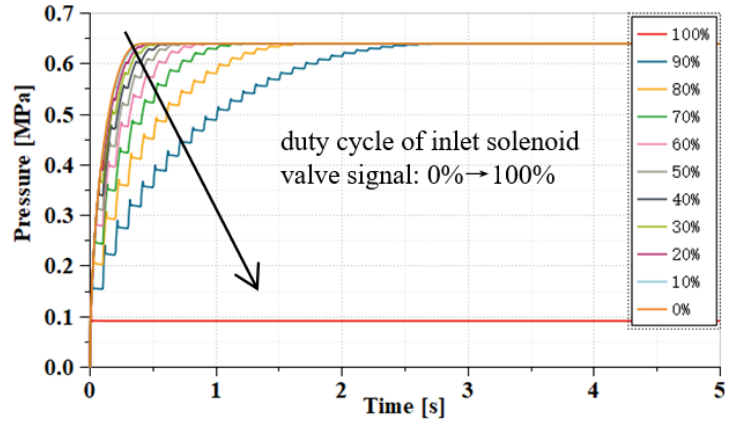

(a)

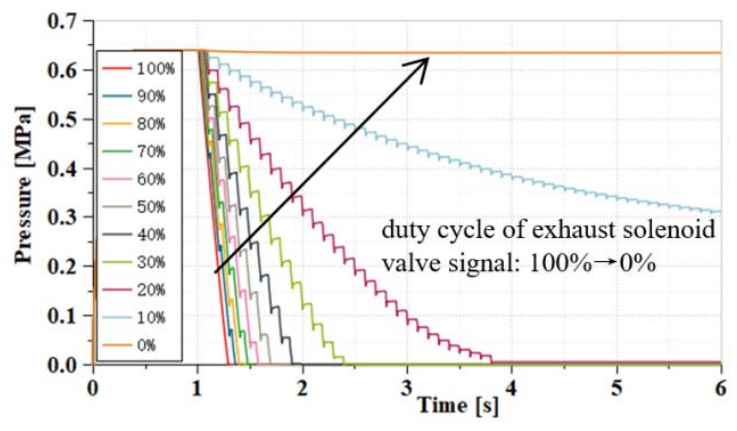

(b)

Figure 11. Pressure response of brake chamber under the control of step charging and step releasing of ABS pressure regulator. (a) Pressure response of step charging; (b) pressure response of step releasing.

\subsection{Verification of the Series Dual-Chamber Air Brake Valve Model}

The input variable of the series dual-chamber air brake valve can be force or displacement of the brake pedal. The air supply pressure was set to $1.0 \mathrm{MPa}$. The input signal was set to a displacement of $20 \mathrm{~mm}$ in the brake pedal within $0.5 \mathrm{~s}$. Then kept the displacement for 1s. Finally, removed the displacement within $0.5 \mathrm{~s}$ [12]. The dynamic curves of the pressure of the outlet ports are shown in Figure 12. The pressure increase has a certain lag, but within an acceptable range. Since there is a long distance between the series dual-chamber air brake valve and the rear brake air chamber, the pressure increase of the rear brake chamber has a certain lag compared with the front brake chamber. The submodel can reflect the dynamic characteristics of the series dual-chamber air brake valve.

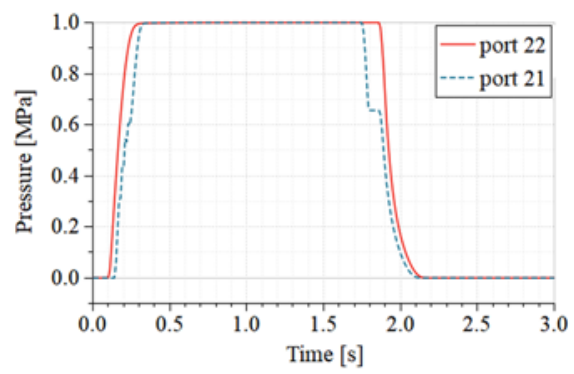

Figure 12. Characteristic curves of series dual-chamber air brake valve. The port 21 is connected to the relay valve control port. The port 22 is connected to the front ABS pressure regulators' inlets.

\subsection{Verification of the Relay Valve Model}

The pressure of air source was set to 1.0 MPa. The high-pressure air was input as a control signal at the control port of the relay valve. The pressure characteristics were obtained as shown in Figure 13. The relationship between control pressure and outlet pressure is approximately linear. Before the control pressure reaches $1.0 \mathrm{MPa}$, the outlet pressure has reached $1.0 \mathrm{MPa}$, thereby achieving a fast inflation function and reducing the pressure hysteresis of the rear brake chamber. The trends of control pressure and outlet pressure are consistent with the actual situation. The simulation results show that the submodel can reflect the characteristics of the relay valve. The reliability of the relay valve model can be verified by the reliability of the total model. 


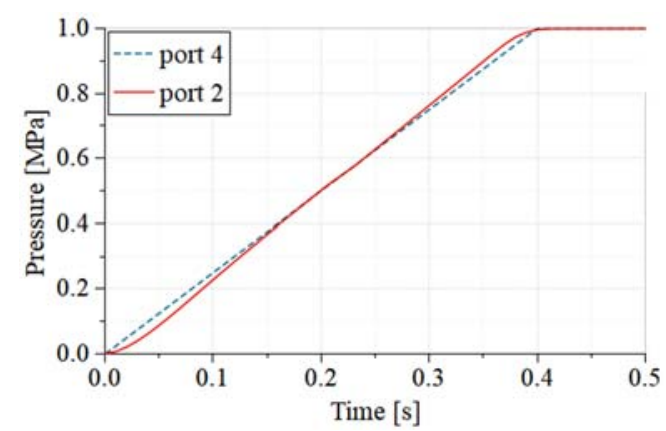

(a)

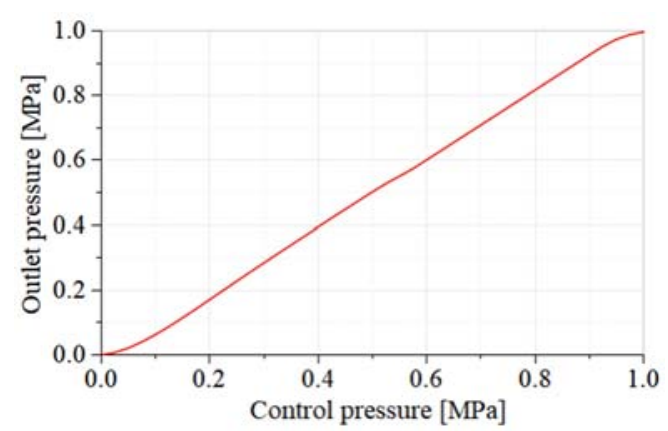

(b)

Figure 13. Characteristic curves of the relay valve. (a) Pressure of the control port and the outlet port; (b) relationship of the outlet pressure and control pressure. Port 2 is the outlet port. Port 4 is the control port.

\subsection{Verification of the Total Model}

In reference [9], a hardware-in-the-loop test bench was built, and the pneumatic ABS control strategy was introduced into the rapid prototype controller MicroAutoBox. The vehicle model built in the veDYNA software was imported into the Simulator that is a real-time simulation platform developed by dsSPACE. The built-in pneumatic ABS test bench, MicroAutoBox, and Simulator were connected through corresponding signal lines. The Simulator transmitted the real-time simulated vehicle speed and wheel speed to the MicroAutoBox through the signal line. The controller in MicroAutoBox sent control signals to the ABS electromagnetic regulator in the pneumatic ABS test bench based on the real-time driving signal. Consequently, the pressure in the brake chamber was controlled. The pressure sensor on the pneumatic ABS test bench transmitted the pressure signal of the brake chamber to the Simulator. The vehicle model in the Simulator converted the pressure signal into a braking torque signal. It was then added to the vehicle model for real-time simulation. The detailed test method can be found in reference [9].

The simulation parameters were set the same value in reference [9]. The initial parameters of the simulation are shown in Table 4 and Figure 14. The simulation step in AMESim and Simulink were all set to $1 \mathrm{~ms}$. Moreover, the communication interval between AMESim and Simulink was the same as the step size, set to $1 \mathrm{~ms}$. The Stateflow was triggered by both rising and falling edges of a pulse signal with the period $2 \mathrm{~ms}$.

The simulation and test results of the high- and low-adhesion roads are shown in Table 5. The relative error between simulation and test for braking deceleration on the high-adhesion road surface is $7.74 \%$, and that for the low-adhesion road surface is $13.51 \%$. The main cause of the error is the simplification of the model, such as the establishment of the suspensions and wheels. The reason for the error may be also related to the difference of the threshold values in the control strategy. Moreover, some parameters of the ABS are not given in reference [9], so we use the real parameters of a pneumatic ABS. The difference of the parameters can also cause errors. The errors are within an acceptable range, so the total model can be considered effective. It is further verified that each submodel is also workable.

In order to investigate whether the control strategy is effective, emergency braking condition simulations were performed on the road surface with adhesion coefficients $0.8,0.6$, and 0.2 . The values of initial vehicle speed were set to $80 \mathrm{~km} / \mathrm{h}, 80 \mathrm{~km} / \mathrm{h}$, and $60 \mathrm{~km} / \mathrm{h}$, respectively. The simulation results are shown in Figures 15-17. 
Table 4. Initial parameters of simulation.

\begin{tabular}{cccc}
\hline Parameter & Symbol & Unit & Value \\
\hline Truck body mass & $m$ & $\mathrm{~kg}$ & 8830 \\
Free tire radius & $r$ & $\mathrm{~mm}$ & 522 \\
Height of mass center & $h_{\mathrm{g}}$ & $\mathrm{mm}$ & 915 \\
x-position of truck body COG (Center of Gravity) & $a$ & $\mathrm{~mm}$ & 1542 \\
Wheel base & $L$ & $\mathrm{~mm}$ & 3880 \\
Front wheel inertia & $I_{\mathrm{wf}}$ & $\mathrm{kg} \cdot \mathrm{m}^{2}$ & 20 \\
rear wheel inertia & $I_{\mathrm{wr}}$ & $\mathrm{kg} \cdot \mathrm{m}^{2}$ & 25 \\
maximum pressure & $P_{\max }$ & $\mathrm{MPa}$ & 1.0 \\
\hline
\end{tabular}

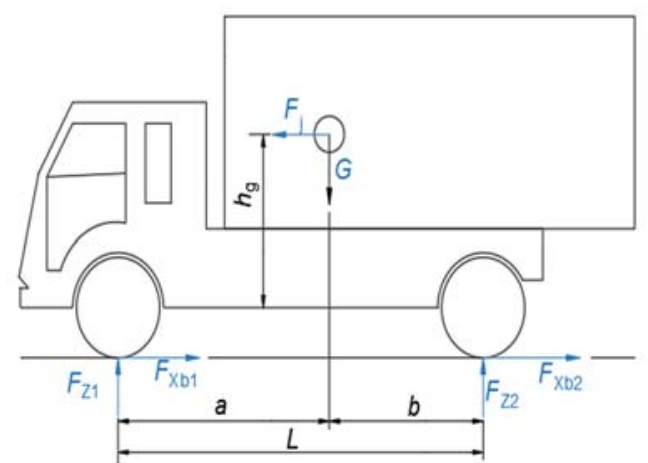

Figure 14. Force diagram of the vehicle braking condition.

Table 5. Comparison of deceleration of simulation and experiment.

\begin{tabular}{|c|c|c|c|}
\hline \multirow{2}{*}{ Adhesion Coefficient } & \multicolumn{3}{|c|}{ Deceleration } \\
\hline & Simulation $\left(\mathrm{m} / \mathrm{s}^{2}\right)$ & Experiment $\left(\mathrm{m} / \mathrm{s}^{2}\right)$ & Error $(\%)$ \\
\hline 0.8 & 7.50 & 6.98 & 7.74 \\
\hline 0.2 & 1.48 & 1.71 & 13.51 \\
\hline
\end{tabular}




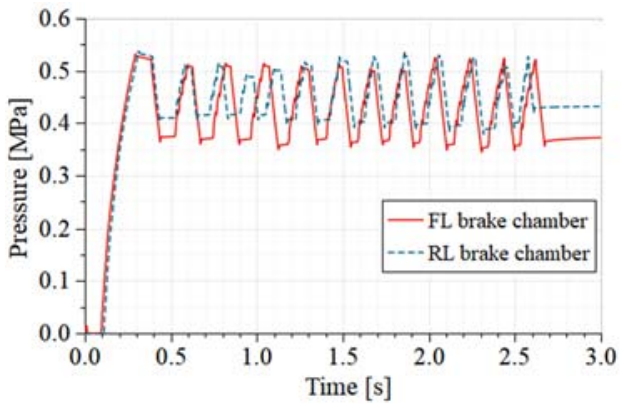

(a)

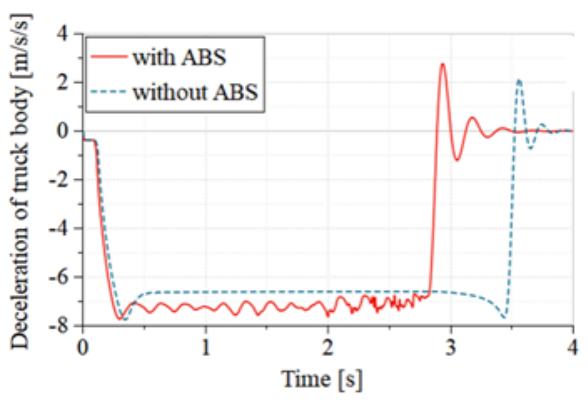

(c)

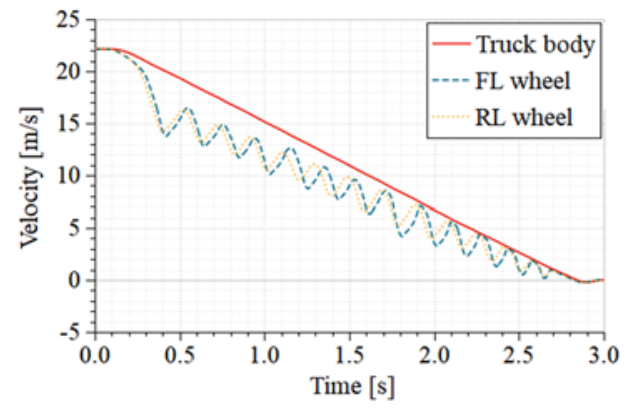

(b)

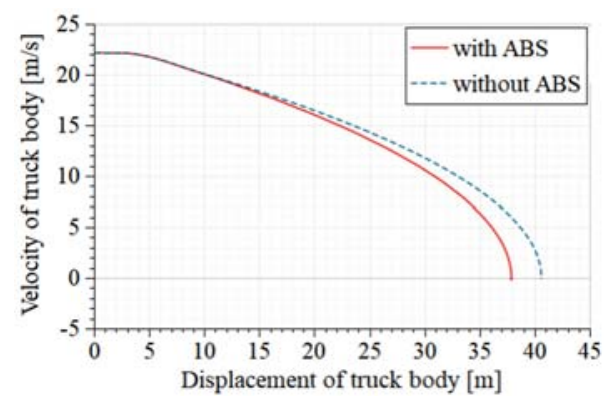

(d)

Figure 15. Braking characteristics on the road with the adhesion coefficient 0.8. (a) Pressure of brake chamber; (b) velocity of truck body and wheels; (c) deceleration of truck body with ABS and without ABS; (d) velocity-displacement curves of truck body with ABS and without ABS.

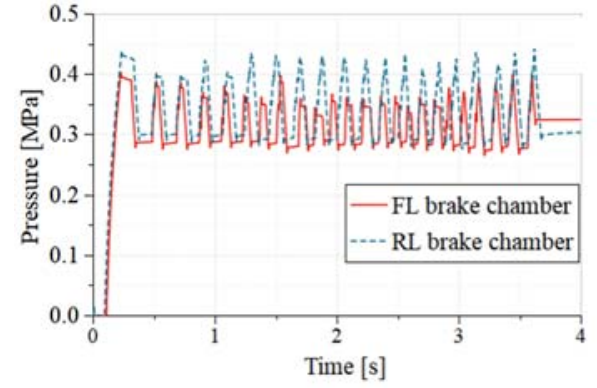

(a)

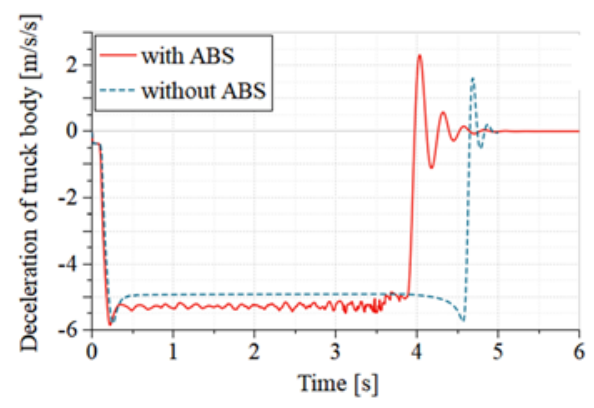

(c)

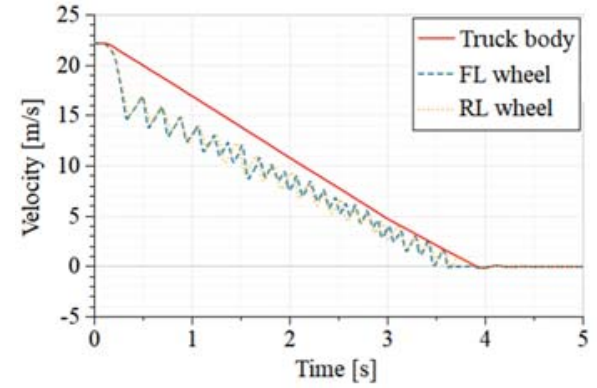

(b)

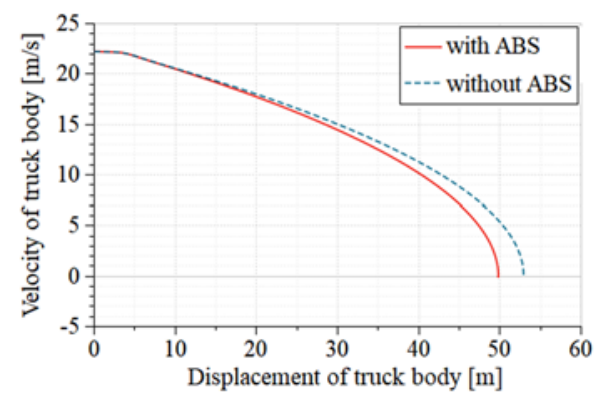

(d)

Figure 16. Braking characteristics on the road with adhesion coefficient 0.6. (a) Pressure of brake chamber; (b) velocity of truck body and wheels; (c) deceleration of truck body with ABS and without ABS; (d) velocity-displacement curves of truck body with ABS and without ABS. 


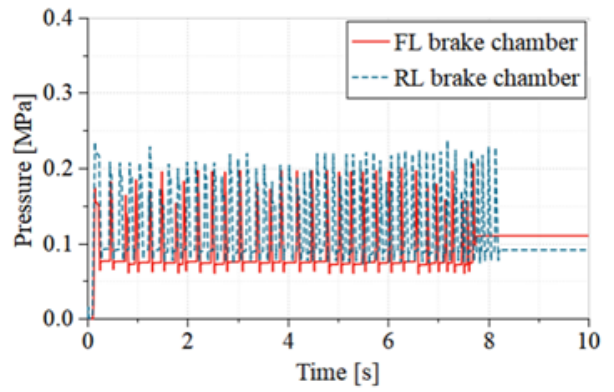

(a)

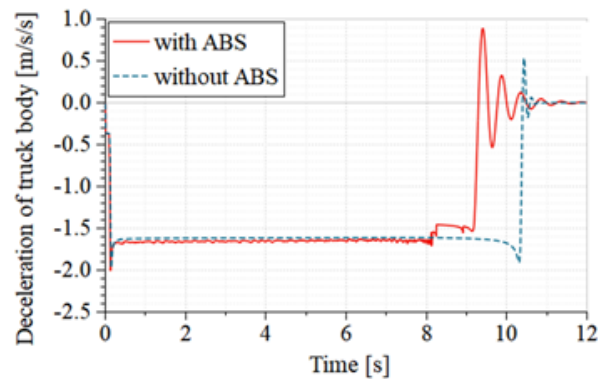

(c)

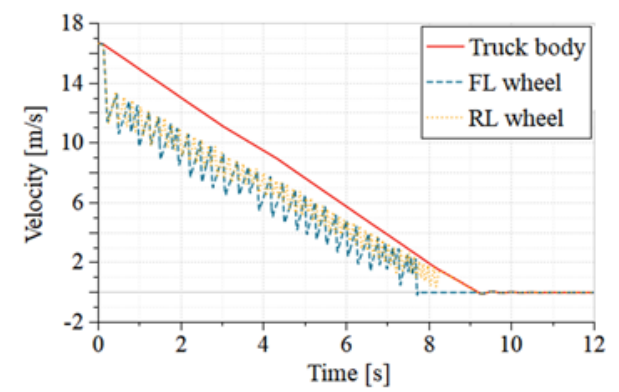

(b)

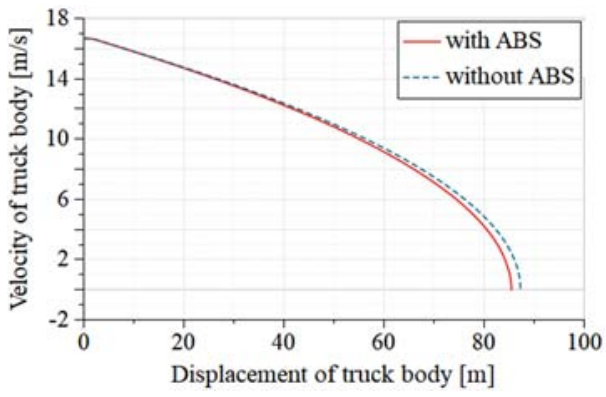

(d)

Figure 17. Braking characteristics on the road with adhesion coefficient 0.2. (a) Pressure of brake chamber; (b) velocity of truck body and wheels; (c) deceleration of truck body with ABS and without ABS; (d) velocity-displacement curves of truck body with ABS and without ABS.

The braking performance of the truck can be evaluated by MFDD (Mean Fully Developed Deceleration). The MFDD is expressed as:

$$
\operatorname{MFDD}=\frac{\left(u_{b}^{2}-u_{e}^{2}\right)}{25.92\left(s_{e}-s_{b}\right)}
$$

where, $u_{\mathrm{b}}=0.8 u_{0}, u_{\mathrm{e}}=0.1 u_{0}, s_{\mathrm{b}}$ is the distance the truck passes from $u_{0}$ to $u_{b}, s_{\mathrm{e}}$ is the distance the truck passes from $u_{0}$ to $u_{e}, u_{0}$ is the initial velocity.

The values of the MFDD are shown in Table 6. $\phi$ is the adhesion coefficient of the road.

Table 6. The MFDD of the truck on the roads with different adhesion coefficients.

\begin{tabular}{ccccccc}
\hline$\phi$ & $\boldsymbol{u}_{\mathbf{0}}(\mathbf{k m} / \mathbf{h})$ & $\boldsymbol{u}_{\mathbf{b}}(\mathbf{k m} / \mathbf{h})$ & $\boldsymbol{u}_{\mathbf{e}}(\mathbf{k m} / \mathbf{h})$ & $\boldsymbol{s}_{\mathbf{b}}(\mathbf{m})$ & $\boldsymbol{s}_{\mathbf{e}}(\mathbf{m})$ & MFDD $\left(\mathbf{m} / \mathbf{s}^{2}\right)$ \\
\hline 0.8 & 80 & 64 & 8 & 16.01 & 37.50 & 7.27 \\
0.6 & 80 & 64 & 8 & 19.86 & 49.33 & 5.28 \\
0.2 & 60 & 48 & 6 & 31.54 & 84.54 & 1.65 \\
\hline
\end{tabular}

As can be seen from Figures 15-17 and Table 6, on the road surface with $\phi 0.8,0.6$, and 0.2, the values of MFDD are $7.27 \mathrm{~m} / \mathrm{s}^{2}, 5.28 \mathrm{~m} / \mathrm{s}^{2}$, and $1.65 \mathrm{~m} / \mathrm{s}^{2}$ respectively. The values of braking strength are $0.742,0.54$, and 0.17 respectively. The adhesion coefficient utilization rates are $92.8 \%, 90.0 \%$, and $84.0 \%$. The braking distances are reduced by $2.684 \mathrm{~m}, 3.106 \mathrm{~m}$, and $1.796 \mathrm{~m}$ respectively. All the adhesion coefficient utilization rates are greater than $75 \%$ and meet the requirements [26]. In the high-, medium-, and low-adhesion roads, the controller can adjust the brake pressure to prevent wheels from locking. The average deceleration of the vehicle with ABS is greater than that without ABS. The model can be considered reliable and can be used in the analysis of failure conditions. 


\section{Analysis of Failure Conditions}

The simulations of different failure ratios were performed based on the reliability of the verified model. First, we selected the component as the analysis object, then we set different parameter values of the selected components to simulate the different failure ratios. Finally, we ran the model and the simulation data were collected and analyzed.

\subsection{Parameters Setting of Failure Modes}

The reduction of the flow area causing by the stuck of the lower chamber piston of the series dual-chamber air brake valve was marked as mode1. The reduction of the flow area of the relay valve was marked as mode2. The rising of the solenoid resistance of the pilot inlet solenoid valve and the pilot exhaust solenoid valve of the ABS pressure regulator were marked as mode3 and mode4, respectively. For the mode3 and mode4, the FL(Front-Left) pressure regulator was taken to analyzed. The normal mode was marked as mode 0 .

\section{(1) Parameters setting of mode1}

In the mode1, the pressure of the front brake pipelines increases slowly, and the pressure of rear brake pipelines increases normally. The failure ratio was simulated by setting the flow area of the component PNAO001 of the lower chamber. The flow area can be expressed as $A=\pi \cdot d s \cdot x$, as shown in Figure 18. The value of $x$ was changed to obtain a different flow area.

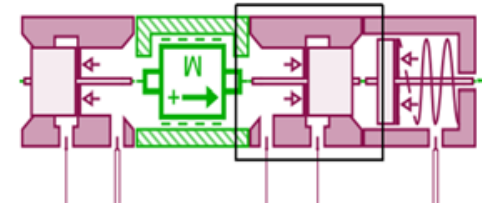

(a)

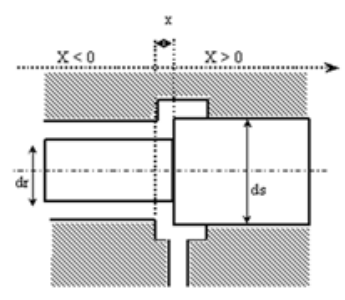

(b)

Figure 18. AMESim submodel and structure diagram of the lower chamber of series dual-chamber air brake valve. (a) Submodel of the lower chamber of series dual-chamber air brake valve; (b) diagram of spool valve with annular orifice of PNAO001.

\section{(2) Parameters setting of mode2}

In the failure mode2, the air cannot enter the rear brake pipeline through the relay valve fluently, so the rear brake cannot work normally, but the front brake works normally. The different failure ratios were simulated by setting the flow area of the relay valve port. The flow area can be expressed as $\mathrm{A}=\pi\left(d i^{2}-d r^{2}\right) / 4$, as shown in Figure 19. The values of $d i$ and $d r$ were changed to get different flow area.

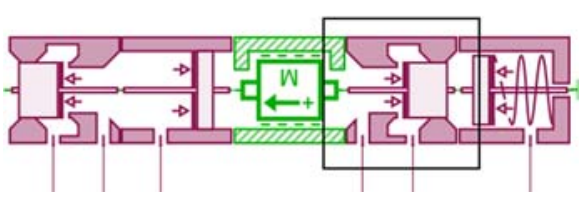

(a)

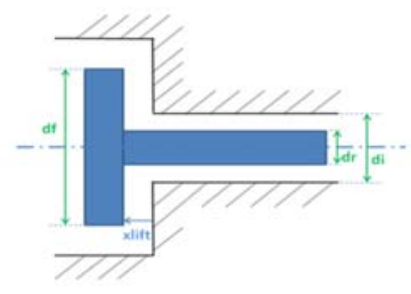

(b)

Figure 19. AMESim submodel of relay valve and structure diagram of the component PNAP031. (a) Submodel of the relay valve; (b) structure diagram of the component PNAP031. 
(3)Parameters setting of mode3 and mode4

The working voltage of the solenoid valve is $24 \sim 28 \mathrm{~V}$, and the normal resistance of the solenoid coil is $16 \Omega$. As can be seen from Table 1 , the solenoid valves are energized for a long time, and overheating will cause the aging of the solenoid. When it ages, the resistance value will become larger than 16 $\Omega$ [30]. This makes the electromagnetic force fail to completely overcome the elastic force of the return spring, so that the solenoid valve cannot be fully opened. The solenoid valve input signal is the current value. The different failure ratios were simulated by changing the value $k$ of the gain module, as shown in Figure 20.

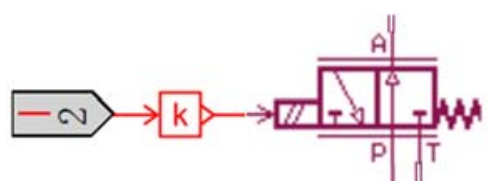

Figure 20. AMESim submodel and structure diagram of pilot inlet and exhaust solenoid valves.

The above four failure modes are common failure modes. Taking the initial condition of the adhesion coefficient 0.6 and the initial velocity $80 \mathrm{~km} / \mathrm{h}$ as an example, the failure mode simulations were carried out. Failure modes were compared with the mode0, and the braking dynamic characteristics of the truck in the above failure modes were studied.

\subsection{Comparison of the Complete Failure Condition of the Four Failure Modes}

The flow area of the component PNAO001 of mode1 was set to 0 , that is, the front brake system did not work. The PNAP031 flow area of mode2 was set to 0 , that is, the rear brake system did not work. The value $k$ of the gain module of mode 3 was set to 0 , that is, the pilot inlet solenoid valve did not work. The value $k$ of the gain module of mode 4 was set to 0 , that is, the pilot exhaust solenoid valve did not work. The deceleration and velocity-displacement are shown in Figure 21.

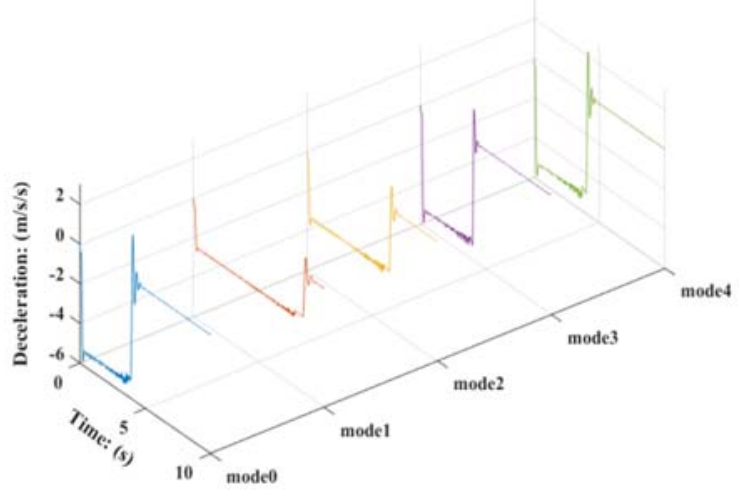

(a)

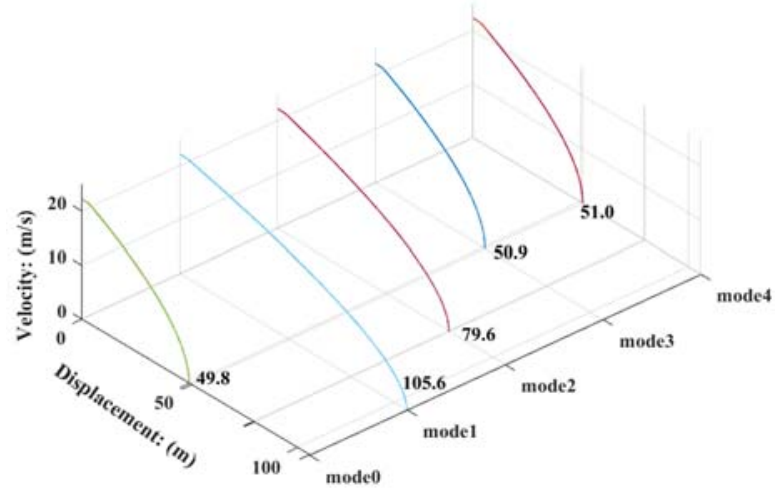

(b)

Figure 21. Braking efficiency of mode 0 and complete failure of mode1 4. (a) Deceleration of truck body; (b) velocity-displacement curves of truck body.

It can be seen from the Figure 21, the braking efficiency of mode 1 and mode 2 was weakened more compared with mode 3 and mode4. Taking the transferring of the axle load into consideration in the design of the braking system, the ground normal reaction force of the front wheel is greater than that of the rear wheel. The distributive coefficient of the braking force must be set, $\beta=F_{\mu 1} /\left(F_{\mu 2}+F_{\mu 1}\right)$. The value of $\beta$ is generally 0.5 0.7. Where, $F_{\mu 1}$ is the braking force of the front brake, where $F_{\mu 2}$ is the braking force of rear brake. The braking factor of the front brake is greater than that of the rear 
brake. The failure of the lower chamber of the series dual-chamber air brake valve is a more dangerous condition, causing a significant increase in the braking distance.

In the complete failure mode 3 and mode4, the brake chamber pressures, the velocities of the truck body, and wheel speeds are shown in the Figure 22. It can be seen that the complete failure of the pilot inlet and exhaust solenoid valves of the ABS pressure regulator led the wheel to be locked. The wheel was locked earlier under mode3 than under mode4, and the advance time was about 0.2s.

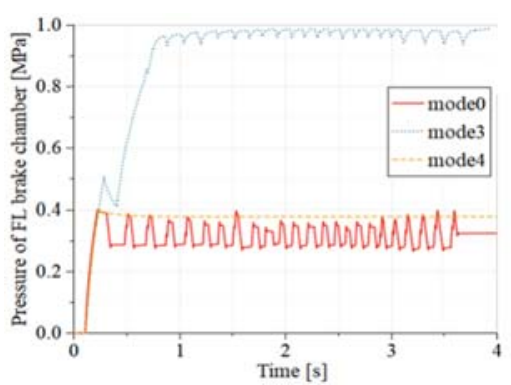

(a)

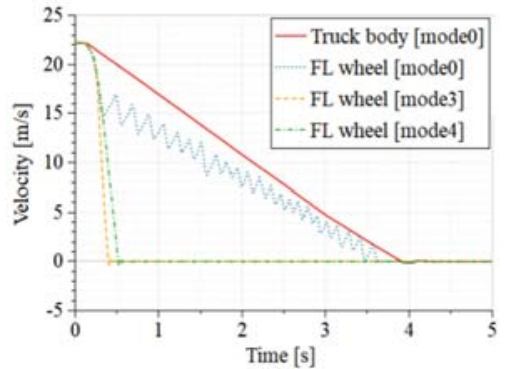

(b)

Figure 22. (a) Pressure of brake chamber at mode0, mode3, and mode4; (b) velocity of the truck body and wheels at mode 0 , mode3, and mode 4 .

\subsection{Effect of Different Failure Ratios on the ABS Performance}

Simulations were performed at 20\%, 40\%, 60\%, 80\%, and 100\% failure ratios for the four failure modes. The simulation results corresponding to the different failure ratios of the four failure modes are shown in Table 7. The Displacement is the braking distance. The values of MFDD were calculated by Equation (1). The symbol $t$ is the time of the braking process. $0 \%$ means mode $0 ; 100 \%$ means completely failure. Three groups of simulations were added to mode 1 and mode 2 from $80 \%$ to $100 \%$, which were omitted in the table.

Table 7. Simulation result at different failure ratios.

\begin{tabular}{|c|c|c|c|c|c|c|c|}
\hline \multicolumn{2}{|c|}{ Failure Ratio (\%) } & 0 & 20 & 40 & 60 & 80 & 100 \\
\hline \multirow{4}{*}{ Failure mode1 } & Displacement (m) & 49.80 & 50.35 & 50.47 & 50.82 & 51.58 & 105.57 \\
\hline & $\operatorname{MFDD}\left(\mathrm{m} / \mathrm{s}^{2}\right)$ & 5.30 & 5.298 & 5.298 & 5.290 & 5.284 & 2.40 \\
\hline & $t(\mathrm{~s})$ & 3.910 & 3.940 & 3.946 & 3.970 & 4.012 & 8.419 \\
\hline & Displacement (m) & 49.80 & 50.15 & 50.23 & 50.35 & 50.83 & 79.66 \\
\hline \multirow[t]{3}{*}{ Failure mode2 } & $\operatorname{MFDD}\left(\mathrm{m} / \mathrm{s}^{2}\right)$ & 5.30 & 5.29 & 5.28 & 5.28 & 5.28 & 3.23 \\
\hline & $t(\mathrm{~s})$ & 3.910 & 3.931 & 3.952 & 3.947 & 3.976 & 6.334 \\
\hline & Displacement (m) & 49.80 & 50.97 & 50.96 & 50.95 & 50.95 & 50.94 \\
\hline \multirow[t]{3}{*}{ Failure mode3 } & $\operatorname{MFDD}\left(\mathrm{m} / \mathrm{s}^{2}\right)$ & 5.30 & 5.170 & 5.168 & 5.167 & 5.169 & 5.168 \\
\hline & $t(\mathrm{~s})$ & 3.910 & 4.010 & 3.991 & 3.996 & 3.996 & 3.992 \\
\hline & Displacement (m) & 49.80 & 50.93 & 50.94 & 50.94 & 50.93 & 50.93 \\
\hline \multirow[t]{2}{*}{ Failure mode 4} & MFDD (m/s²) & 5.30 & 5.167 & 5.167 & 5.167 & 5.167 & 5.167 \\
\hline & $t(\mathrm{~s})$ & 3.910 & 4.010 & 4.010 & 4.010 & 4.010 & 4.010 \\
\hline
\end{tabular}

In order to more intuitively show the influence of the failure ratios on the braking performance, the simulation result of the relationships of vehicle velocity and braking distance are shown in Figure 23. Brake pressure curves of different failure ratios are shown in Figure 24. 


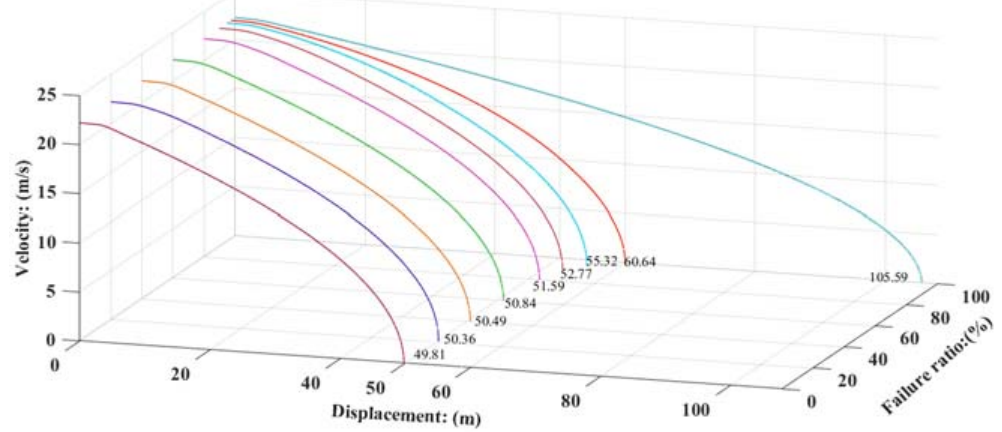

(a)

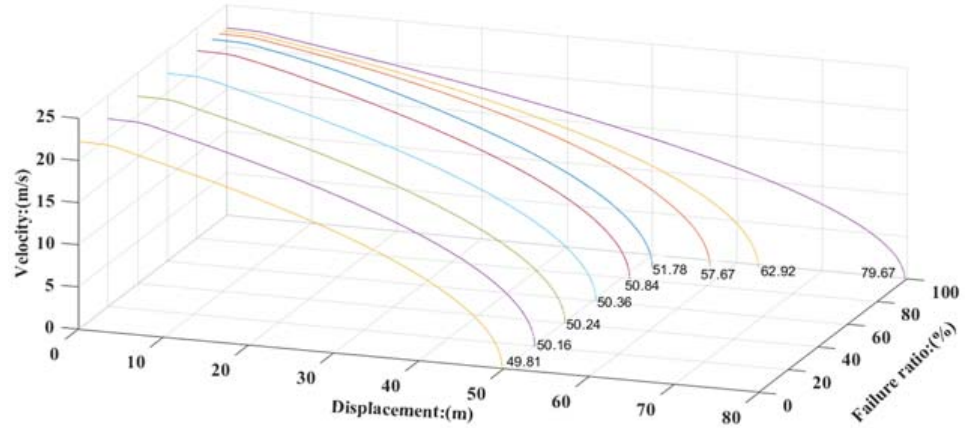

(b)

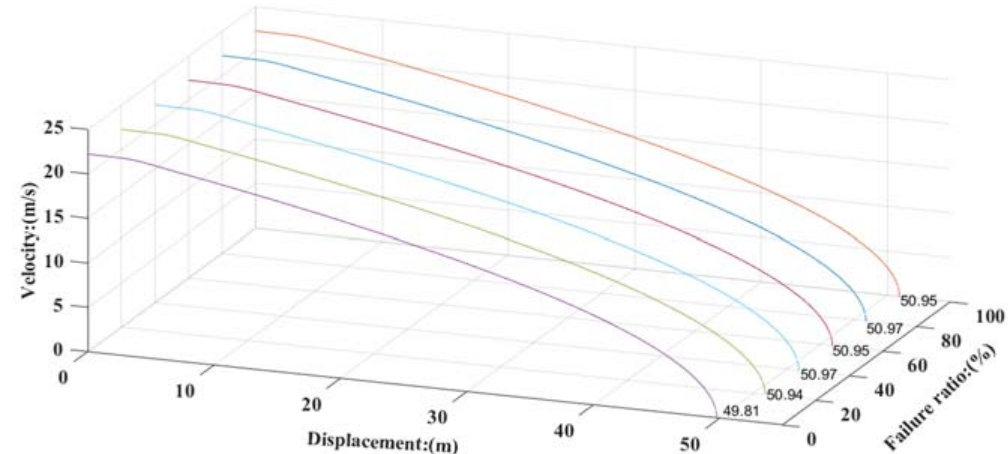

(c)

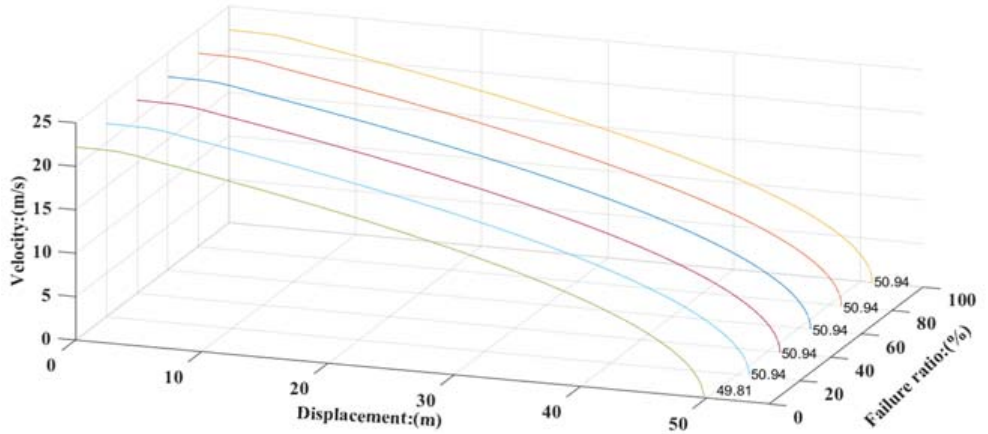

(d)

Figure 23. Velocity-displacement curves of different failure ratios. (a) mode1; (b) mode2; (c) mode3; (d) mode4. 


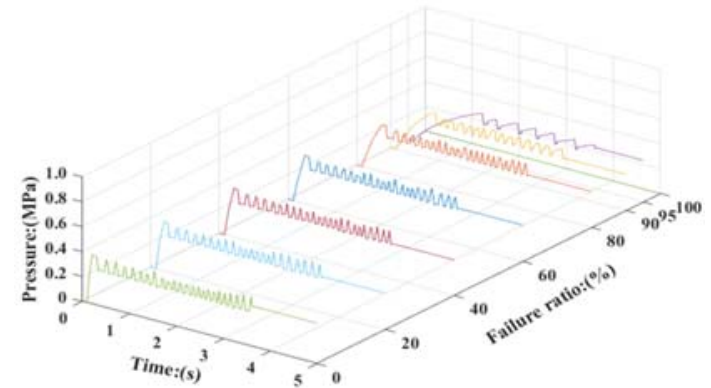

(a)

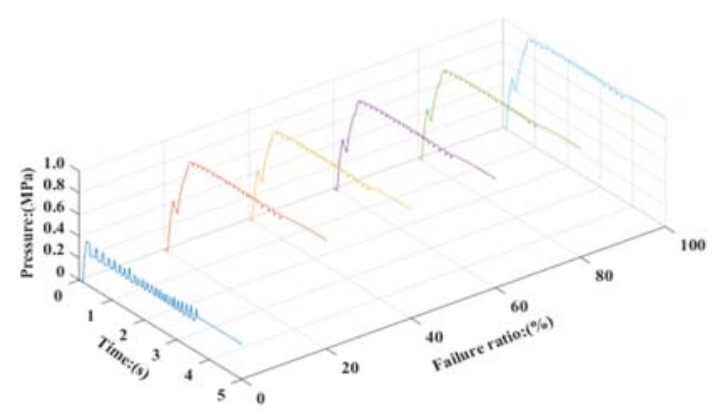

(c)

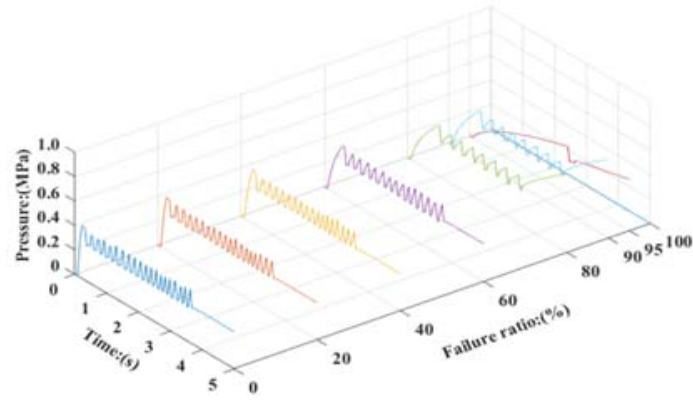

(b)

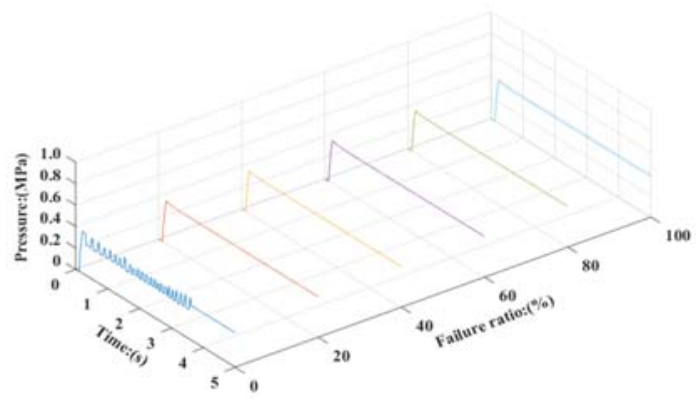

(d)

Figure 24. Pressure of brake chamber of different failure ratios. (a) mode1(FL); (b) mode2(RL); (c) mode3(FL); (d) mode4(FL).

Mode1 mainly affects the ability of the front brakes. The FL wheel was taken as an example for analysis. From curves as shown in Figures 23a and 24a, it can be seen that the relationship between the braking distance and the failure ratio is nonlinear. When the failure ratio reaches over about $80 \%$, the braking distance increases quickly. From the curves of pressure, it can be seen that the greater the failure ratio, the more obvious the throttling effect of the pipeline, the slower the pressure increase, and the more the ABS intervention time lags. The peak adhesion coefficient can not be utilized effectively, so the braking ability is reduced. In mode0, the ABS intervention time is about $0.3 \mathrm{~s}$. When the failure ratio reaches $90 \%$, the ABS intervention time is about $0.9 \mathrm{~s}$. In case of complete failure, the air flow becomes zero and the front brake completely loses braking capacity.

Mode2 mainly affects the ability of rear brakes. The RL wheel was taken as an example for analysis. From the curves shown in Figures 23b and 24b, it can be seen that the characteristics of the influence on braking distance of failure ratio are similar to mode1. With the decrease of the flow area, the pressure hysteresis of the rear brake chamber becomes more obvious. In mode0, the ABS intervention time is about $0.3 \mathrm{~s}$. When the failure ratio of mode 2 reaches $80 \%$, the ABS controller starts to intervene at $1.01 \mathrm{~s}$. When the relay valve fails completely, the flow rate becomes 0 , and the rear brake chamber pressure is maintained at atmospheric pressure. The rear brake completely loses braking ability.

Mode3 weakens the braking ability of the single wheel. The FL wheel was taken as an example for analysis. From Figure 23c, it can be seen that the increase of braking distances are almost equal at different failure ratios. The pressure of the brake chamber is shown in Figure 24c. When the solenoid fails, the electromagnetic force of the spool cannot overcome the spring force of the return spring, which causes the inlet valve not close normally, thus the ABS pressure regulator lose the ability of pressure holding and the pressure releasing. The pressure of the chamber rises to a maximum value in a short time and fluctuates slightly around the maximum value. The braking torque of the brake is kept near the maximum value that is greater than the road-braking torque, and the wheel is locked.

Mode4 was analyzed by taking the FL wheel as an example. Figure 23d shows the increase of braking distances are almost equal at different failure ratios. The pressure of brake chamber at different 
failure ratios is shown in Figure $24 \mathrm{~d}$. When the pilot exhausted solenoid valve fails, under the action of the return spring, the exhaust valve was normally closed. The ABS pressure regulator loses the ability of pressure releasing. Under the action of the controller, the pilot inlet solenoid valve opened and the inlet valve closed. The ABS pressure regulator remained in the state of pressure holding. The brake chamber pressure increases to the maximum value of the first cycle, and then the pressure remains constant. The wheel eventually locked.

\section{Conclusions}

The purpose of this paper is to investigate the dynamic response characteristics and failure characteristics of typical ABS failure modes, and to analyze the effects of failure modes on vehicle braking performance. Modeling, analysis, and experimental verification were carried out. The main conclusions are as follows:

(1) a pneumatic ABS co-simulation model of trucks based on AMESim and Simulink was established. The model considered the influence of pipeline length, resistance, temperature, and air pressure hysteresis caused by each valve orifice. The test proves that the model is workable.

(2) Submodels can reflect their real pressure dynamic characteristics. The interface module can perform data interaction. The controller can effectively adjust the braking force to prevent the wheel from locking. The mean errors between the simulation and the experiment are not more than $13.51 \%$.

(3) Four failure modes were simulated and analyzed. In the mode1 and mode2, when the failure ratio reaches over about $80 \%$, the throttle effect of the pipeline begins to play a significant role, the pressure increase hysteresis becomes obvious, and the ABS intervention time delays, resulting in a significant increase in the braking distance. In the mode 3 and mode4, the failure of different ratios of pilot inlet and exhaust solenoid valves results in the corresponding wheel lock. The effect of failure ratios on the braking distance is not obvious.

The modeling and simulation can be referred to fault diagnosis of pneumatic ABS. The co-simulation method can be used in fluid-solid coupling simulation. Moreover, the model can also be applied to steering stability simulation and ABS control strategy development of commercial vehicles. The ABS co-simulation model based on the 3D vehicle model will be established. More effects of failure modes such as the failure of a single ABS pressure regulator on the driving direction of the vehicle during braking will be further studied. In the follow-up study, more tests will be carried out to further verify the model and improve the accuracy of the model.

Author Contributions: Data curation, X.L. (Xiaohan Li); Formal analysis, X.L. (Xiaohan Li); Funding acquisition, L.Z. and C.Z.; Investigation, L.Z.; Methodology, C.Z.; Software, H.L.; Supervision, L.Z.; Writing - original draft, X.L. (Xiaohan Li); Writing - review and editing, X.L. (Xue Li) All authors have read and agreed to the published version of the manuscript.

Funding: This work was supported by the Scientific Research Starting Foundation for Doctors (419067), National Natural Science Foundation of China (51575325), and School-Enterprise Cooperation Project(2018-KJ-4).

Conflicts of Interest: The authors declare no conflict of interest.

\section{References}

1. Gong, T.; Yan, H.; Liu, P.F. Modeling and Simulation for Anti-Lock Braking System (ABS) of Automobiles Based on Simulink. In Applied Mechanics and Materials; Trans Tech Publications: Stafa-Zurich, Switzerland, 2015; Volume 716-717, pp. 1504-1507. [CrossRef]

2. Cao, F.P.; Chen, C.M.; Zhou, L.F. Research on Simulation of Anti-Lock Braking System Based on MATLAB. In Advances in Engineering Research, Proceedings of the 2018 3rd International Conference on Automation, Mechanical Control and Computational Engineering (AMCCE 2018), May 2018; Atlantis Press: Paris, French, 2018; Volume 166, pp. 839-844. [CrossRef]

3. Ma, T.F.; Chen, Q. The Modeling and Simulation of Pneumatic ABS Pressure Regulator Based on AMESim. Adv. Mater. Res. 2014, 971-973, 811-815. [CrossRef] 
4. Wang, Q.N.; Yang, Y.; Jin, L.Q. Research on ABS Regulation of Electric Vehicle Driven by In-Wheel Motors by AMESim Co-Simulation with Matlab/Simulink. In Proceedings of the International Conference on System Science, Engineering Design and Manufacturing Informatization (ICSEM), Guiyang, China, 22-23 October 2011; IEEE: Piscataway, NJ, USA, 2011; pp. 227-232.

5. Zhao, Q.; Duan, J.J.; Wang, C. Modeling and Simulation of Vehicle Hydraulic ABS Based on AMESim. In Advanced Materials Research; Trans Tech Publications: Stafa-Zurich, Switzerland, 2012; Volume 590, pp. 441-445.

6. Wang, J.; Song, C.X.; Jin, L.Q. Modeling and Simulation of Automotive Four-Channel Hydraulic ABS Based on AMESim and Simulink/Stateflow. In Proceedings of the 2010 2nd International Workshop on Intelligent Systems and Applications, Wuhan, China, 22-23 May 2010; IEEE: Piscataway, NJ, USA, 2010.

7. Wang, J.; Li, J.H.; Jin, L.Q.; Song, C.X. Research on the Joint Modeling and Simulation of Automotive ABS based on AMESim and Simulink/Stateflow. Automob. Technol. 2010, 1, 25-28+33.

8. Lu, Y.; Zhou, J.H.; Lu, J.; Guo, B. Research on comprehensive performance test system for proportional relay valve of commercial vehicle EBS. In Journal of Physics: Conference Series; IOP Publishing Ltd.: München, Germany, 2018; p. 1074.

9. Kong, D.J. Research on Pneumatic ABS Control Strategy Based on State Machine Algorithm. Master's Thesis, Jilin University, Changchun, China, 2016.

10. Lin, H.; Song, C.X. Design of a Fuzzy Logic Controller for ABS of Electric Vehicle Based on AMESim and Simulink. In Proceedings of the 2011 International Conference on Transportation, Mechanical, and Electrical Engineering (TMEE), Changchun, China, 16-18 December 2011; IEEE: Piscataway, NJ, USA, 2012.

11. Liu, X.X.; Wang, R.; Yuan, L. Design and Analysis on the Anti-Lock Braking Control System of a Four-Wheel Vehicle. Appl. Mech. Mater. 2015, 599-601, 864-869. [CrossRef]

12. Chen, $Q$. The Simulation Research of Pneumatic Braking System's Dynamic Characteristic for Commercial Vehicle. Master's Thesis, Jilin University, Changchun, China, 2015.

13. Zheng, T.X.; Ma, F.L.; Yang, Y.; Jiang, G.Y. Research on Pneumatic ABS Generalized Predictive Control. In Proceedings of the 2010 8th World Congress on Intelligent Control and Automation, Jinan, China, 7-9 July 2010; IEEE: Piscataway, NJ, USA, 2010.

14. Zhao, Y.M.; Zhang, J.Z.; Li, C.; He, C.K. Sliding Mode Control Algorithm for Regenerative Braking of an Electric Bus with a Pneumatic Anti-lock Braking System. IOP Conf. Ser. Mater. Sci. Eng. 2019, 538, 012067. [CrossRef]

15. Minh, V.T.; Oamen, G.; Vassiljeva, K.; Teder, L. Development of Anti-lock Braking System (ABS)for Vehicles Braking. Open Eng. 2016, 6, 554-559. [CrossRef]

16. Naderi, P.; Farhadi, A.; Mirsalim, M.; Mohammadi, T. Anti-Lock and Anti-Slip Braking System, Using Fuzzy Logic and Sliding Mode Controllers. In Proceedings of the Vehicle Power and Propulsion Conference (VPPC), Lille, France, 1-3 September 2010; IEEE: Piscataway, NJ, USA, 2010.

17. Mokarram, M.; Khoei, A.; Hadidi, K. a fuzzy Anti-lock braking system (ABS) controller using CMOS circuits. Microprocess. Microsyst. 2019, 70, 47-52. [CrossRef]

18. Dang, B.Y. Study on the Control of Anti-Lock Braking System Simulation Based on Fuzzy PID Control. Adv. Mater. Res. 2014, 950, 239-244. [CrossRef]

19. Gu, Z.Q.; Hu, S.Y.; Yang, F.; Yang, R.; Hua, J. a New Calculating Method of Pressure Response Time of Pneumatic Brake Pipe Based on Experiments. Math. Probl. Eng. 2019, 2019, 1039474. [CrossRef]

20. Chu, L.; Hou, Y.L.; Liu, M.H.; Li, J.; Gao, Y.M.; Ehsani, M. Study on the Dynamic Characteristics of Pneumatic ABS Solenoid Valve for Commercial Vehicle. In Proceedings of the Vehicle Power and Propulsion Conference, Arlington, TX, USA, 9-12 September 2007; IEEE: Piscataway, NJ, USA, 2008.

21. Tao, J.M.; Wang, B.H. Study of the Dynamic Threshold and Control Logic on Anti-Lock Brake System (ABS). In Proceedings of the International Vehicle Electronics Conference (IVEC'99) (Cat. No.99EX257), Changchun, China, 9 September 1999; IEEE: Piscataway, NJ, USA, 2002.

22. Natarajan, S.V.; Subramanian, S.C.; Darbha, S.; Rajagopal, K.R. a model of the relay valve used in an air brake system. Nonlinear Anal. Hybrid Syst. 2007, 1, 430-442. [CrossRef]

23. Zhang, H.H.; Wu, J.L.; Chen, W.; Zhang, Y.Q.; Chen, L.P. Object Oriented Modeling and Simulation of a Pneumatic Brake System with ABS. In Proceedings of the 2009 IEEE Intelligent Vehicles Symposium, Xi'an, China, 3-5 June 2009; IEEE: Piscataway, NJ, USA, 2009. 
24. Meng, W.X. Research on Detecting System of Pneumatic Brake Regulator Control Characteristics for Commercial Vehicle. Master's Thesis, Chongqing University of Technology, Chongqing, China, 2012.

25. Meng, W.X.; Luo, H.; Jiang, Q.; Pan, Z.B.; Feng, H.J. Modeling of Pneumatic ABS Regulator Based on AMESim and its Characteristics Analysis. Mach. Electron. 2011, 9, 37-40.

26. Hu, K.A. Research of Control Method for Pneumatic ABS Based on Logic Threshold Method. Master's Thesis, Hunan University, Changsha, China, 2013.

27. Jung, S.P.; Jun, K.J.; Park, T.W.; Yoon, J.H. Development of the brake system design program for a vehicle. Int. J. Automot. Technol. 2008, 9, 45-51. [CrossRef]

28. Tao, Z.K.; Tian, C.; Wu, M.L. Fault Simulation of Relay Valve Based on AMESim. In Applied Mechanics and Materials; Trans Tech Publications: Stafa-Zurich, Switzerland, 2013; Volume 241.

29. Ji, W.; Chen, Z.Y.; Li, Q. Failure Research of Vehicle ABS Based on Fuzzy Diagnosis Technology. Adv. Mater. Res. 2014, 912-914, 675-678. [CrossRef]

30. Yang, K.; Ma, C.; Guo, D.; Gao, S.; Wang, J.; Ren, L.P.; W, J.L. Failure analysis and improvement of pneumatic ABS solenoid valve for URBS of new energy bus. J. Guangxi Univ. (Nat. Sci. Ed.) 2017, 42, 1647-1656.

31. Chen, J.R. Automobile Structure; China Machine Press: Beijing, China, 2009.

32. Fu, Y.L.; Qi, X.Y. Reference Manual of LMS Imagine. In Lab AMESim System Modeling and Simulation; Beihang University Press: Beijing, China, 2011.

33. Fu, Y.L.; Qi, H.T. Tutorial Examples of LMS Imagine. In Lab AMESim System Modeling and Simulation; Beihang University Press: Beijing, China, 2011.

34. Ren, F.; Yu, Y.L. Research on Flexible Network Plan Simulation Based on Stateflow. In Proceedings of the 2010 International Conference on Electrical and Control Engineering, Wuhan, China, 25-27 June 2010; IEEE: Piscataway, NJ, USA, 2010.

35. Yu, F. Automotive System Dynamics; Machinery Industry Press: Beijing, China, 2016.

36. Yu, Z.S. Automobile Theory; China Machine Press: Beijing, China, 2009.

(C) 2020 by the authors. Licensee MDPI, Basel, Switzerland. This article is an open access article distributed under the terms and conditions of the Creative Commons Attribution (CC BY) license (http://creativecommons.org/licenses/by/4.0/). 